This item was submitted to Loughborough's Research Repository by the author.

Items in Figshare are protected by copyright, with all rights reserved, unless otherwise indicated.

\title{
Sales intra-functional flexibility: Its relationship to performance and moderating effects on role stressors
}

PLEASE CITE THE PUBLISHED VERSION

https://doi.org/10.1016/j.jbusres.2018.12.021

PUBLISHER

(C) Elsevier

VERSION

AM (Accepted Manuscript)

PUBLISHER STATEMENT

This paper was accepted for publication in the journal Journal of Business Research and the definitive published version is available at https://doi.org/10.1016/j.jbusres.2018.12.021.

LICENCE

CC BY-NC-ND 4.0

\section{REPOSITORY RECORD}

Micevski, Milena, Belinda Dewsnap, John Cadogan, Selma Kadic-Maglajlic, and Nathaniel Boso. 2019. "Sales Intra-functional Flexibility: Its Relationship to Performance and Moderating Effects on Role Stressors". figshare. https://hdl.handle.net/2134/36875. 


\title{
Sales intra-functional flexibility: Its relationship to performance and moderating effects on role stressors
}

\author{
Milena Micevski ${ }^{\text {a, * }}$ \\ milena.micevski@univie.ac.at \\ Belinda Dewsnap ${ }^{b}$ \\ b. dewsnap@lboro.ac.uk \\ John W. Cadogan b, e \\ j.w.cadogan@lboro.ac.uk \\ Selma Kadic-Maglajlic ${ }^{c}$ \\ selma.kadic@efsa.unsa.ba \\ Nathaniel Boso ${ }^{d}$ \\ nboso@knust.edu.gh
}

\footnotetext{
${ }^{\text {a }}$ University of Vienna, Faculty of Business, Economics and Statistics, Department of International Marketing, Oskar-Morgenstern Platz 1, 1090, Vienna, Austria

${ }^{b}$ School of Business and Economics, Loughborough University, Epinal Way, Loughborough, Leicestershire LE11 3TU, UK

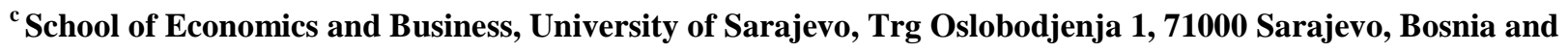
Herzegovin

${ }^{\text {d }}$ KNUST School of Business, Kwame Nkrumah University of Science and Technology, Kumasi, Ghana

${ }^{\text {e }}$ LUT School of Business and Management, LUT University, Skinnarilankatu 34, 53850 Lappeenranta, Finland)
}

${ }^{*}$ Corresponding author 


\title{
Sales intra-functional flexibility: its relationship to performance and moderating effects on role stressors
}

\author{
Abstract \\ Building on strategic flexibility literature and social exchange theory, we identify sales \\ department intra-functional flexibility (SIF) as an important driver of sales organization success. \\ Using primary data from 229 sales organizations, we find that sales teams with greater levels of \\ SIF report greater levels of sales and customer performance. In addition, findings show that \\ customer orientation positively moderates SIF's relationship with customer performance, but \\ negatively moderates its effect on the relationship with sales performance. We find mixed results \\ with regard to the benefits of SIF in conditioning the effect of salesperson role stress to firm \\ performance. Theoretical and managerial implications of these findings are discussed and \\ avenues for future research are proposed.
}

Keywords: sales intra-functional flexibility, strategic flexibility, flexible resource exchange, role stress, customer orientation 


\section{Introduction}

Strategic flexibility is argued to be a core capability underpinning the success of today’s organizations, and researchers are seeking to identify key areas where strategic flexibility needs to be developed and maintained within the firm (e.g. Cadogan, Sundqvist, Puumalainen, \& Salminen, 2012; Dai, Goodale, Byun, \& Ding, 2018; Grewal \& Tansuhaj, 2001; Han, Sung, \& Shim 2014). In dynamic contemporary business environments, sales units are faced with heightened variation and diversity in customer demands and competitor activity that require greater levels of internal collaboration and flexibility in sales unit resources and procedures (e.g. Chonko \& Jones, 2005; Mason \& Mouzas, 2012; Román \& Iacobucci, 2010); this means that strategic flexibility is also relevant to the field of sales management. Accordingly, flexible resource reallocation (Bradford et al., 2010) and coordination of resources within sales units (Rangarajan, Chonko, Jones, \& Roberts, 2004) - hereafter, sales intra-functional flexibility (SIF) - are recognized as being of potential importance.

However, sales research has yet to empirically examine in a systematic way questions pertaining to the performance outcomes of strategic flexibility in the sales context. As a result, the literature does not provide sufficient insights into whether SIF is related to firm performance, and this lack of attention is a concern for two main reasons. First, it is not obvious whether having sales units with high levels of SIF is more or less beneficial for sales organizations. Second, it is not obvious whether there are conditions where SIF's relationships with performance outcomes are greater or weaker. Knowledge on these fronts is critical in helping determine whether fostering, and investing in the development, of SIF is warranted.

In addressing these gaps in the existing sales literature, and in an effort to guide sales 
managers' effective use of sales unit resources, this study proposes to examine the relationship between SIF and organizational performance in the context of varying levels of customer orientation (e.g. Homburg, Müller, \& Klarmann, 2011). There is the possibility that when this orientation is combined with SIF, sales teams may organize internally to focus more intensively on providing customer value, and the knock-on effect of this may be that while customer outcomes (e.g. customer satisfaction) are improved, salespeople’s focus on outcomes more internal to the organization (e.g. sales and market share growth) may take a back seat.

The study also focuses on the role SIF plays in moderating the effect of role stressors on performance. To a certain extent, role stress is endemic in the sales job since salespeople are boundary spanners (e.g. Johnson \& Sohi, 2014; Román, Rodríguez, \& Jaramillo, 2018). Sales role stress encompasses cognitive and resource demands on salespeople with the potential to lower enthusiasm for their sales role (Jones, Chonko, Rangarajan, \& Roberts, 2007) and is shown to adversely affect sales performance (e.g. Jaramillo, Mulki, \& Boles, 2013; Jones et al., 2007). With a pool of available flexible resources provided by SIF, salespeople may have the scope to "hedge" those resources in order to have the room to maneuver in their decisions, and so to better handle the role stress they face.

Thus, this study contributes to the sales literature in several ways. First, we provide a conceptualization of SIF and specify its potency in driving the performance of sales organizations. Second, by examining moderators of the SIF-performance relationship, we identify when SIF may be more or less beneficial to sales organizations. Third, we show that SIF is a boundary condition in the role stress-firm performance relationship with its ability to modify the effects of role stress on firm performance. For managers, the study articulates the importance of building flexible relations within the sales unit, points to the contingencies that diminish the 
benefits of SIF, as well as SIF's possible role in shaping the performance outcomes of role stress.

The next section presents the theoretical background, and outlines a set of hypotheses on the relationships between study variables. We then outline the methods used, and proceed to test the model. We conclude by discussing findings, contribution, and avenues for further research.

\section{Literature, background and hypotheses}

The fundamental premise of strategic flexibility is that "an organization has access to flexible resources and [is] flexible in coordinating those resources in alternative uses” (Sanchez, 1997, p. 73). Given firms' resource constraints, successful leveraging of resources is considered fundamental in taking advantage of emerging customer requirements and changing market needs (Davcik \& Sharma, 2016; Matzler, Sauerwein, \& Heischmidt, 2003). Indeed, according to Sanchez (1997), the flexible use of resources is particularly important, since the way in which firms use resources may enhance or put constraints on strategic flexibility; and so, it is the flexible leveraging of existing resources that is of special interest in the present research. Despite widespread acknowledgement that strategic flexibility plays an important role in organizational success and potentially in an internal sales relationship context, most sales unit level studies tend to concentrate on the individual salesperson and his/her external behavior and relationships with customers (e.g. Hughes, Le Bon, \& Rapp, 2013; Morgan, 2012). Far less attention is directed to understanding how salespeople may engage in internal relational exchanges and, specifically, how they exhibit flexibility in these intra-functional relationships (Bolander \& Richards, 2018; Plouffe, 2018). Accordingly, we turn to social exchange theory (SET) (Blau, 1964) to propose and, in conjunction with Sanchez (1997), define SIF as a unique 
form of relational flexibility. Sanchez (1997) asserts that strategic flexibility "depends jointly on the inherent flexibilities of the resources available for use by the organization and on the organization's flexibilities in applying those resources” (p. 73). Extending this logic, SIF is argued to be a condition of the sales department which is brought about through the joint effects of, (a) having resources that can be flexibly deployed, and (b) the capacity to influence or shape how the redeployed resources are used and configured. Thus, we define SIF as "the extent to which salespeople are able to flexibly reallocate sales resources and then coordinate the use of these resources within the sales unit".

\subsection{SIF and performance}

In our model (Fig. 1), we propose that greater SIF is positively related to sales performance and to customer satisfaction and loyalty. We argue that SIF enables salespeople to respond effectively to pressures coming from an increasingly demanding and competitive market environment and to leverage the resources at the disposal of the entire sales function. The key tenets of SET, reciprocity and exchange, and associated cooperative intentions, will ensure that salespeople exchange resources in a cycle of behaviors, such that the behavior of one member in the (intra-functional) relationship is affected and reciprocated by the behavior of others within the sales unit. Coupled with the notion of mutual adaptation as a necessary part of any on-going relationship (Bercovitz, Jap, \& Nickerson, 2006; Cannon, Achrol, \& Gundlach, 2000), adaptations made by salespeople will be reciprocated in a collaborative manner within the entire sales unit. Inherent within such flexible relationships is the mutual trust, resource sharing and commitment between the partners (Bercovitz et al., 2006; Poppo, Zhou, \& Li, 2016). Greater SIF 
Fig. 1: Conceptual model.

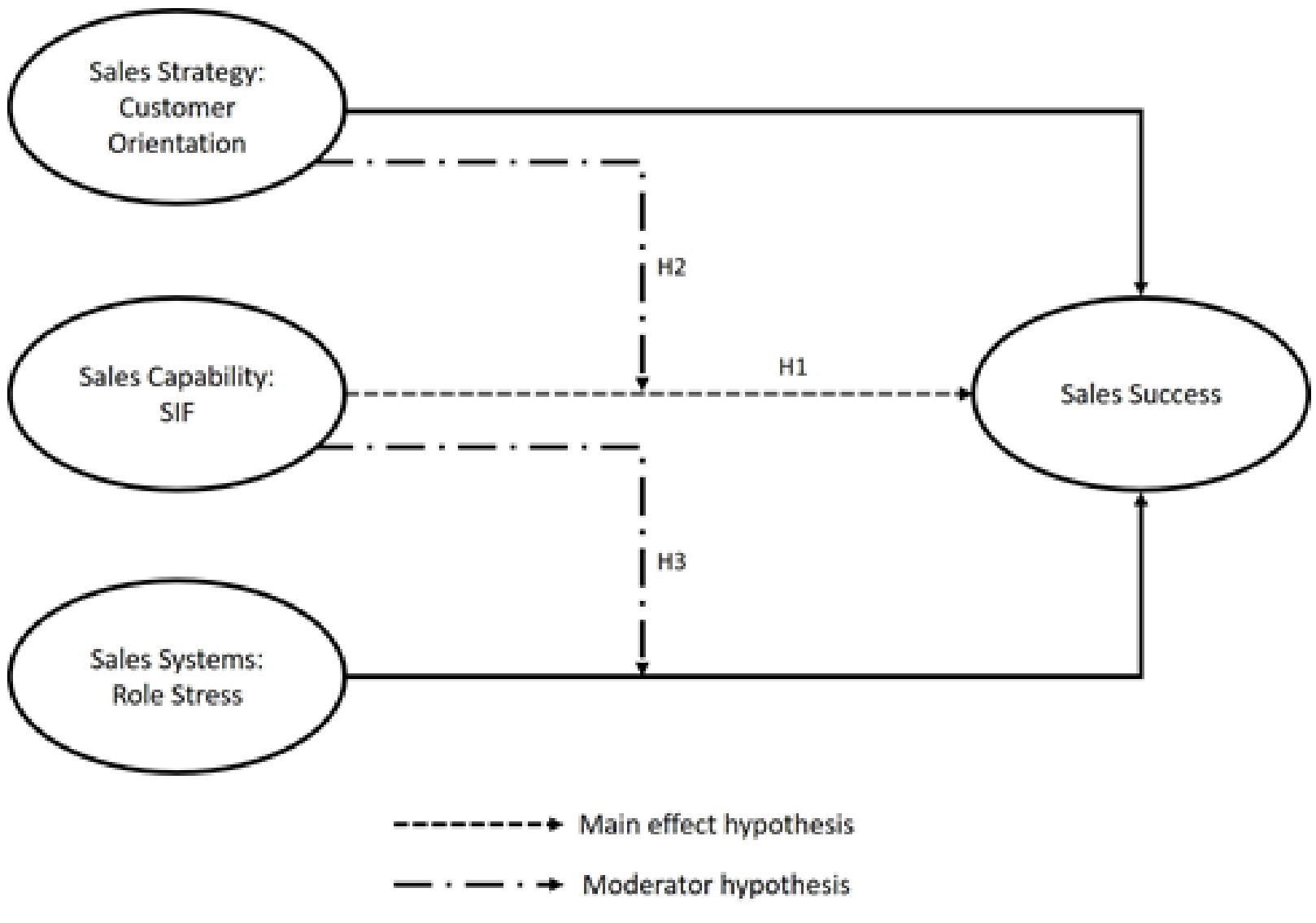

enables harmonization of salespeople’s capabilities across units, and resources can be reallocated and redeployed in new and novel ways to take advantage of market opportunities (Lee \& Xia, 2005). For example, greater flexibility in managing resources ensures that salespeople find it easier and less costly to switch critical resources (e.g. sales personnel and budget) committed to a particular customer segment to an alternative segment. When such flexible intra-functional exchange is high, there is greater willingness of salespeople to support one another emotionally, operationally and logistically, helping build a sense of mutuality and togetherness, which can then be extended to customers. Diverse competencies residing in the sales unit are made 
available to each individual salesperson and are combined to create the space for creative and novel solutions to emerge, with flexible adaptations accurately and appropriately targeted at market opportunities and market threats (Kouropalatis, Hughes, \& Morgan, 2012). Therefore:

H1: SIF is positively related to a) sales and b) customer performance.

\subsection{The moderating role of $\mathrm{CO}$}

The importance of customer orientation (CO) has been widely accepted in the sales literature due to the key role it plays in salespeople’s success (e.g. Wachner, Plouffe, \& Grégoire, 2009). Narver and Slater (1990) defined CO as "the sufficient understanding of one's target buyers to be able to create superior value for them continuously" (p.21). The firm's CO creates an environment in which salespeople are more responsive in respect of addressing customer needs as it furnishes salespeople with the knowledge to better tailor products and services to customers relative to competitors. Hence, we contend that in overall terms $\mathrm{CO}$ will moderate the relationship between SIF and organizational performance. Therefore:

H2: CO moderates the relationship between SIF and firm performance.

However, as we argue below, we expect that $\mathrm{CO}$ will affect different firm outcomes differentially. In a customer-oriented firm it is imperative for salespeople to be responsive to customer needs, using their knowledge to tailor products and services (Wachner et al., 2009). However, there is the possibility that customer orientation, when combined with SIF, may mean that sales teams organize internally to focus more intensively on providing customer value. The 
knock-on effect of this may be that while customer outcomes are improved (e.g. customer satisfaction), salespeople's focus on outcomes more internal to the organization (e.g. sales and market share growth) may be given a lower priority. Hence, higher levels of CO may hinder the effectiveness of SIF on sales performance. By contrast, a greater focus on, and understanding of, customer needs facilitates the positive relationship between SIF and customer satisfaction and loyalty:

H2a: CO negatively moderates the relationship between SIF and sales performance.

H2b: CO positively moderates the relationship between SIF and customer performance.

\subsection{The moderating effect of SIF on role conflict and role ambiguity}

Salespeople as boundary spanners are faced with multiple and often opposing demands from customers and management, all requiring high levels of commitment from the salesperson (Mulki, Jaramillo, Malhotra, \& Locander, 2012). Scarcity of resources available to salespeople will limit the amount of activities and tasks a single salesperson can satisfactorily carry out (Bonney, Plouffe, \& Wolter, 2014; Podsakoff, LePine, \& LePine, 2007). Salespeople often feel under time pressure and experience high levels of uncertainty and conflict, resulting in high role stress. When salespeople feel that their role incorporates incompatible and overlapping demands which interfere directly with their ability to satisfy all the demands at hand, they experience role conflict (RC) (e.g. Betterncourt \& Brown, 2003). When what is expected of salespeople is unclear, they can also suffer from role ambiguity (RA) (Katz \& Kahn, 1978). RC and RA present salespeople with decision-making problems, revolving around determining how to resolve 
conflicts arising from competing job demands, and how to deal with ambiguity in role expectations. Greater levels of SIF may provide salespeople with greater access to resources and to coordinated systems to resolve role stress. If conflicts occur, there are resources at hand to deal with apparently conflicting work objectives, and if ambiguities exist, then with a pool of slack resources, sales people have room to maneuver in their decision making: to make mistakes, to learn what is required of them, and so to handle the stress they face. For instance, when sales people have potentially conflicting sales role objectives (e.g. to provide value for both customers and the sales organization), but have limited capacities to shift resources around and configure those resources, the ability of sales people to resolve conflicts is limited. On the other hand, facilitated by SIF, salespeople can leverage resources to mitigate conflicts. Where salespeople also have the capacity to influence how resources are employed, there is going to be greater opportunity to satisfy multiple seemingly antithetical demands from multiple stakeholders. The chance to resolve RC is thus greater when SIF is higher. Likewise, when salespeople experience high levels of RA, and when salespeople also have more capacity to redeploy and configure resources (greater SIF), the ambiguity can be resolved more easily. This would mean that when SIF is high, salespeople will have more scope to "hedge" those resources for an uncertain future, and more easily mitigate the negative impacts of RA. All in all, the logic implies that SIF allows salespeople to overcome the performance inhibiting impacts of high RC and RA. Thus:

H3: SIF positively moderates the relationships between role stress and, a) sales and b) customer performance. 


\section{Methodology and model testing}

Data collection. Data for the study was collected in a nationwide, multi-industry survey of sales and marketing managers in the United Kingdom. In total, 229 usable questionnaires were obtained (effective response rate $=12 \%$ ). Average respondent experience in a sales position was 11 years. On average, companies employed 300 employees with revenue ranging between $£ 76$ 125 million. To ensure the knowledgeability of the potential respondents, the companies selected for the data collection were, (1) contacted by the researchers to identify the most appropriate respondents for the study, and (2) the latter were contacted to ensure their participation and their topic knowledge. The questionnaires were sent to all the respondents who agreed to participate in the study. A competence measure was included at the end of the questionnaire asking respondents how competent they were in answering the questions in the questionnaire (c.f., Homburg \& Jensen, 2007), and respondents scoring lower than a mean of 5 were excluded from further analysis. The mean value was 6.02 out of 7, indicating knowledgeable respondents.

Measures. All scales were drawn from previous research except for the SIF measure. Customer orientation was adapted from Narver and Slater (1990), role conflict and ambiguity from Rizzo, House and Lirtzman (1970), and sales and customer performance from Hooley, Greenley, Cadogan, and Fahy (2005) and Katsikeas, Leonidou, and Morgan (2000). The measure of SIF was designed to capture the two implicit facets of strategic flexibility proposed by Sanchez (1997, p.73): flexibility in "the resources available for use by the organization" and flexibility “in applying those resources”. First, we sought to capture what we call resource flexibility (hereinafter, RF), which is 'the extent to which the sales department can shift resources from one use to another use'. Second, mapping Sanchez's (1997) idea of the 
organization's flexibility in applying those flexible resources and defining this notion as 'the extent to which salespeople have the ability to influence and shape how these resources are used', we sought to capture what we term configurational flexibility (hereinafter, CF). We interviewed 17 sales and marketing managers and from our discussions with them, created an item bank to measure the constructs. Based on feedback from a panel of five sales and marketing academics and sales managers, items were purified. For instance, to measure RF we retained a question regarding the extent to which the sales department "Is able to shift resources from one sales activity to another" (see Table 1); likewise, for the measure of CF which is about whether sales have the ability to influence how these redeployed resources are used, we asked a question about whether salespeople are persuasive and assertive. ${ }^{1}$ Table 1 provides descriptive statistics, internal consistency reliabilities and a list of items of the variables used in the study.

Scale assessment. Reliability and validity of each construct was evaluated using confirmatory factor analysis in LISREL 8.71, using the covariance matrix as input date. We included all independent and dependent latent variables as well as controls in one multifactorial model, which showed a good fit to the data $\left(\chi^{2} /\right.$ d.f. $=319.54 / 202 ; \mathrm{RMSEA}=.051 ; \mathrm{NNFI}=.942$; CFI=.954; SRMR=.045) (Bentler \& Chou, 1987). Composite reliability (CR) and average variance extracted (AVE) wee above recommended thresholds of .60 and .50, respectively (Bagozzi \& Yi, 1988) as per Table 2, and all constructs exhibited discriminant validity, with all AVE scores greater than the squared correlations between each pair of constructs (Fornell \& Larcker, 1981).

\footnotetext{
${ }^{1}$ Full details on the scale development procedure are available from the authors upon request.
} 
Table 1. Construct measurement and validation.

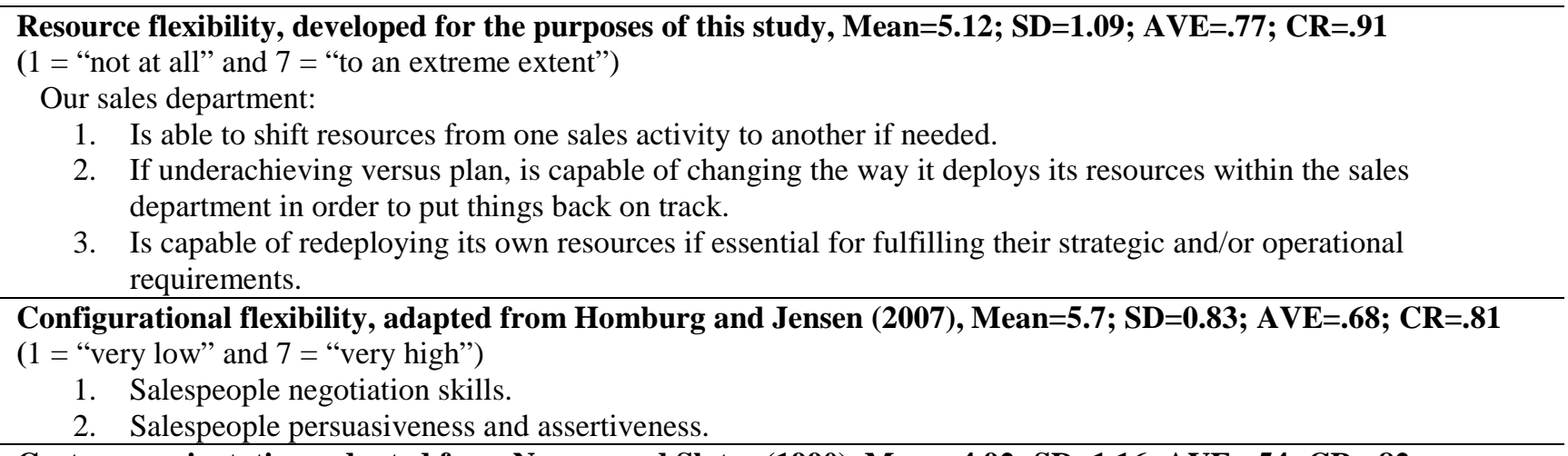

Customer orientation, adapted from Narver and Slater (1990), Mean=4.92; SD=1.16; AVE=.54; CR=.82

( 1 = "far less than expected," and 7 = "much higher than expected")

1. Our business strategies are driven by our beliefs about how we can create greater value for our customers.

2. Our strategy for competitive advantage is based on our understanding of our customers' needs.

3. Our business objectives are driven primarily by customer satisfaction.

4. We give close attention to after-sales service for our customers.

Role conflict, adapted from Rizzo et al. (1970), Mean=4.17; SD=1.18; AVE=.50; CR=.75

$(1=$ "not at all" and $7=$ "to an extreme extent")

Salespeople:

1. Have to "bend a rule" or policy in order to carry out an assignment.

2. Have to do things that, in their opinion, should be done differently.

3. Do things that are accepted by one person and not by others (e.g. managers, colleagues, customers).

Role ambiguity, adapted from Rizzo et al. (1970), Mean=4.00; $\mathrm{SD}=1.04 ; \mathrm{AVE}=.62 ; \mathrm{CR}=.87$

( 1 = "not at all" and 7 = "to an extreme extent")

Salespeople are:

1. Have clear, planned goals and objectives for their jobs. (R)

2. Know what their job responsibilities are. (R)

3. Have very clear explanations of what has to be done on the job. (R)

4. Know exactly what is expected of them. (R)

Sales performance, taken from Hooley et al. (2005) and Katsikeas et al. (2000), Mean=5.00; SD=1.32; AVE=.76;

$\mathrm{CR}=.864$

(1 = "very dissatisfied" and 7 = "very satisfied")

1. Satisfaction with the company's sales volume during the past 3 years.

2. Satisfaction with the company's market share during the past 3 years.

Customer performance, taken from Hooley et al. (2005), Mean=5.00; $\mathrm{SD}=1.05 ; \mathrm{AVE}=.69 ; \mathrm{CR}=.87$

(1 = "very dissatisfied" and 7 = "very satisfied")

1. Levels of customer loyalty compared to competitors?

2. Levels of customer satisfaction compared to last year?

3. Levels of customer loyalty compared to last year?

Note: (R) - item reverse coded

Additional data were collected from independent sources (FAME database) to validate

our performance measures (Luo, Rindfleisch, \& Tse, 2007). Turnover and number of employees

for 176 firms was obtained. We correlated the objective measures with those provided by 
respondents. The results indicate a good, strong correlation between subjective and objective measures of performance. To test for potential bias in our data we first used the marker variable technique (Podsakoff, MacKenzie, Lee, \& Podsakoff, 2003). A partial correlation analysis of the items measuring our constructs indicate that the significance of the zero-order correlations remained unchanged when the marker variable (i.e. marketing's functional identity) was partialed out, thus suggesting that common method bias is not a problem. We also correlated a six-item formative social desirability scale (Luo et al., 2007) with each of the study constructs. The correlations are all non-significant (highest correlation between RA and SD =.103), indicating that social desirability do not have an effect on respondents’ answers.

Hypothesis testing. In order to test hypotheses about SIF, we controlled for the interaction between RF and CF. This was done in accordance with Sanchez's (1997) idea of strategic flexibility which suggests that the impact of strategic flexibility emerges from the joint effects of RF and CF. Further, before performing the analysis and to test the interaction effects of the three moderators (CO, RC and RA), the standard procedure as recommended by Ping (1995) and Aiken and West (1991) was performed. Namely, given the limited sample size for a model with all specified interaction terms to be estimated, model complexity was reduced by using single item indicators for the latent variables involved in the interaction terms (CO, RC and RA), and following Little, Bovaird, and Widaman's (2006) procedure for orthogonalizing the observed interactions. Specifically, our assessment of moderating effect is based on product term analysis (Aiken \& West, 1991). Therefore, our analysis is based on an estimation of relationships 
between interaction terms (products of the main effect variable and the moderator variable) and outcome variables, where all interaction terms are specified as single-item constructs. The single indicant for $\mathrm{CO}$ was multiplied by the single indicant for RF to create a COxRF product term; this was then orthogonalized and used in the subsequent analysis (in this particular case, H2).

Table 2. Discriminant Validity of the Constructs

\begin{tabular}{lccccccccccccccccc}
\hline & 1 & 2 & 3 & 4 & 5 & 6 & 7 & 8 & 9 & 10 & 11 \\
\hline Resource flexibility & $\mathbf{0 . 7 7 3}$ & 0.049 & 0.001 & 0.032 & 0.005 & 0.038 & 0.000 & 0.014 & 0.008 & 0.019 & 0.012 \\
Configurational flexibility & 0.221 & $\mathbf{0 . 6 7 9}$ & 0.000 & 0.116 & 0.009 & 0.053 & 0.011 & 0.000 & 0.003 & 0.008 & 0.003 \\
Role conflict & 0.038 & -0.022 & $\mathbf{0 . 5 0 2}$ & 0.038 & 0.000 & 0.023 & 0.000 & 0.008 & 0.001 & 0.000 & 0.000 \\
Role ambiguity & -0.179 & -0.340 & 0.196 & $\mathbf{0 . 6 2 2}$ & 0.000 & 0.051 & 0.012 & 0.022 & 0.000 & 0.009 & 0.009 \\
Customer orientation & 0.074 & 0.094 & -0.012 & -0.017 & $\mathbf{0 . 5 3 7}$ & 0.005 & 0.092 & 0.043 & 0.001 & 0.001 & 0.000 \\
Customer performance & 0.194 & 0.231 & -0.153 & -0.225 & 0.068 & $\mathbf{0 . 6 8 7}$ & 0.008 & 0.002 & 0.001 & 0.006 & 0.001 \\
Sales performance & -0.009 & 0.106 & 0.017 & 0.110 & 0.303 & 0.091 & $\mathbf{0 . 7 6 0}$ & 0.000 & 0.003 & 0.000 & 0.005 \\
Environmental dynamism & -0.118 & 0.012 & 0.090 & -0.147 & 0.207 & -0.049 & 0.012 & $\mathbf{0 . 6 7 4}$ & 0.002 & 0.001 & 0.000 \\
Type of commerce & 0.089 & 0.058 & 0.026 & -0.004 & 0.035 & 0.034 & -0.057 & -0.047 & N/A & 0.024 & 0.043 \\
transaction & 0.138 & 0.087 & 0.021 & -0.093 & 0.035 & -0.074 & -0.017 & 0.034 & -0.156 & N/A & 0.068 \\
Sales department size & -0.111 & -0.051 & -0.002 & 0.096 & 0.013 & -0.033 & -0.068 & -0.015 & 0.207 & -0.261 & N/A \\
Company experience & & & & & &
\end{tabular}

Note: Correlations are below the diagonal, squared correlations are above the diagonal, and AVE estimates are presented on the diagonal.

We also controlled for variables that have been shown in past research to affect performance (i.e. company experience, the size of the sales department, type of industry and type of commerce transaction) (e.g. Sturman, 2003; Wieseke, Ahearne, Lam, \& Dick, 2009).

Finally, in order to test our hypotheses, we ran a series of hierarchical multiple regressions in which we ran increasingly complex models, adding the moderator variables in blocks while controlling for main effects and control variables. 


\section{Results}

Table 3a and 3b show the results of the regression analyses for all hypotheses. For sales performance (Table 3a), model 1 serves as the baseline model and includes the control variables only. This model generated a moderate effect size (Cohen, 1988), with an $\mathrm{R}^{2}$ of $0.170(\mathrm{p}<.05)$. Role ambiguity (RA) and Customer Orientation (CO) are positively and significantly related to sales performance ( $<<.05$ and $\mathrm{p}<.01$, respectively), whereas role conflict $(\mathrm{RC})$ is non-significant. In model 2, we added the first-order terms for resource (RF) and configurational flexibility (CF) as well as their multiplicative term. As a result, $\mathrm{R}^{2}$ increased to $0.196(\mathrm{p}<.10)$. The coefficient for CF is significant and positive $(\mathrm{p}<.05)$, while coefficients for RF and the multiplicative term are non-significant. In model 3, we added the interaction terms for CO and SIF, generating a slightly higher $\mathrm{R}^{2}=0.218(\mathrm{p}<.10)$. Only the interaction of $\mathrm{CO}$ and $\mathrm{RF}$ is significant and has a negative direction ( $\mathrm{p}<.05)$. In model 4 we further added the interaction terms for RC and the two SIF facets. This resulted in higher $\mathrm{R}^{2}=.227$ (ns.). The coefficient for the interaction term created between RC and RF is significant at the $10 \%$ level. Finally, in model 5 we added the interaction between RA and SIF which resulted in a substantial effect size (Cohen, 1988), with $\mathrm{R}^{2}$ of 0.276 $(\mathrm{p}<.05)$. Both interaction terms (for RA and RF, and RA and CF) are significant, where the coefficient for RA and RF interaction term is positive $(\mathrm{p}<.01)$ and $\mathrm{RA}$ and $\mathrm{CF}$ is negative $(p<.01)$. All the differences are provided in Table 3a. We rely on model 5 to interpret our results.

The same pattern of analysis was followed for customer performance (Table 3b). In model 1, RA and RC have a significant and negative relationship to customer performance ( $\mathrm{p}<.01$ and $\mathrm{p}<.10$, respectively), whereas $\mathrm{CO}$ has a positive effect ( $\mathrm{p}<.10)$. In model 2 both $\mathrm{RF}$ and CF are positively and significantly related to customer performance ( $\mathrm{p}<.05$ both), as well as 
their interaction term $(\mathrm{p}<.05)$. In model 3 we added the interaction term created by multiplying CO and SIF. CO positively moderates the relationship between RF and customer performance $(\mathrm{p}<.05)$. In model 4 we added the interaction terms for RC and SIF. Neither of the two interactions between RC and RF and RC and CF are significant. Finally, in model 5 the interaction between RA and RF is found to be positive and significant $(\mathrm{p}<.05)$, whereas the interaction between RA and CF is non-significant. For customer performance, $\mathrm{R}^{2}$ increased as we moved from model 1 to model 5 as shown in Table 3b. Considering the significance in F changes as we move from model 1 to model 5, we rely on model 3 to interpret our results (as per, for example, Lassala, Burrus, \& Graham, 2016).

Hypotheses test results. First, the results of multiple regression analysis indicate that the two notions of SIF are positively related to both sales and customer performance. Specifically, CF has positive relationships with both sales $(\mathrm{p}<.05)$ and customer performance $(\mathrm{p}<.01)$, while $\mathrm{RF}$ is positively related to customer performance $(\mathrm{p}<.05)$. However, and more importantly, in addition to including SIF's two components - RF and CF - as direct predictors of sales and customer performance, in order to control for the potential that strategic flexibility emerges from the joint effects of resource and configurational flexibilities (Sanchez, 1997), we included the multiplicative interaction of RF and CF in the regressions. These interactions are significant and positive ( $<$ <.01 and $\mathrm{p}<.10$ for sales and customer performance, respectively). Therefore, supporting $\mathrm{H} 1$, the results are consistent with the notion that RF and CF positively impact both sales and customer performance. More specifically, our results indicate that firm performance is higher in instances where the sales department has resources that can be shifted from one use to another use (i.e. resource flexibility) and has the capacity to influence or shape how the 
redeployed resources are used (i.e. configurational flexibility). Jointly, these two facets of flexibility are related to sales and customer performance positively.

In $\mathrm{H} 2$ we argue for a negative moderation of customer orientation (CO) on the SIF-sales relationship and a positive moderation in the case of the SIF-customer performance link. Here and as discussed below, we receive full support as RF's relationship with sales performance is negatively moderated by $\mathrm{CO}(\mathrm{p}<.05)$, while RF's relationship with customer performance is positively moderated by $\mathrm{CO}(\mathrm{p}<.05)$.However, the hypothesized relationships in $\mathrm{H} 2$ involving customer performance present a surprising finding. Notably, the direct CO-customer performance relationship, although in the expected positive direction, is not significant; this main effect is against usual expectations. As a possible explanation, we note that $\mathrm{CO}$ is a firm level strategy that has to be enacted by the firm's personnel, including salespeople. Of course, salespeople are acutely aware of the importance of customer performance outcomes, as these are inextricably linked to salesperson performance outcomes. However, in a situation where CO in a firm is low, individual salespeople still need to achieve customer satisfaction and loyalty in order to maintain sales. In these situations, salespeople may compensate to some extent for low levels of firm CO by developing strong inter-personal relationships with customers, seeking to enhance customer outcomes despite the organizational strategy.

By contrast, CO directly is a significant, positive predictor of sales performance (sales volumes and market share). We might expect this because with greater customer insight and more sophisticated segmentation, the firm can capture new customers in existing markets, expand more easily into related markets, create new markets, and so on. However, as anticipated, 
Table 3a. Hypotheses testing results for dependent variable: sales performance

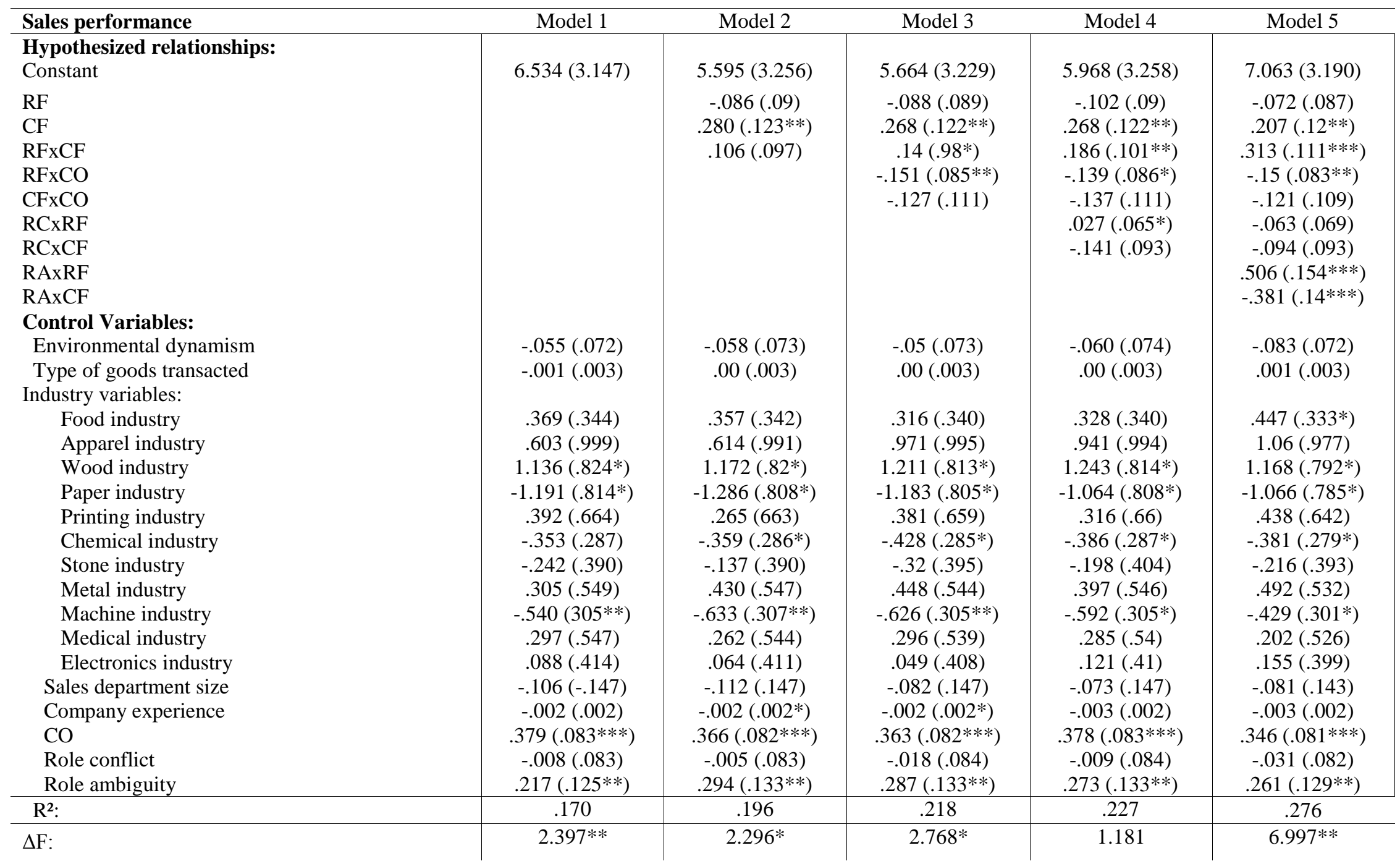

Note: RF-Resource flexibility; CF-Configurational flexibility; RC-Role conflict; RA-Role ambiguity; CO-Customer orientation; Standard errors are in parentheses. Coefficients are unstandardized. ${ }^{* * *} \mathrm{p}<.01 ;{ }^{* *} \mathrm{p}<.05 ;{ }^{*} \mathrm{p}<.10$ 
Table 3b. Hypotheses testing results for dependent variable: customer performance

\begin{tabular}{|c|c|c|c|c|c|}
\hline Customer performance & Model 1 & Model 2 & Model 3 & Model 4 & Model 5 \\
\hline \multicolumn{6}{|l|}{ Hypothesized relationships: } \\
\hline Constant & $7.228(2.316)$ & $5.030(2.363)$ & $4.981(2.345)$ & $5.093(2.377)$ & $5.6292(2.387)$ \\
\hline $\mathrm{RF}$ & & $.116\left(.065^{* *}\right)$ & $.117\left(.065^{* *}\right)$ & $.119\left(.065^{* *}\right)$ & $.126\left(.065^{* *}\right)$ \\
\hline $\mathrm{CF}$ & & $.199(.089 * *)$ & $.207(.89 * * *)$ & $.205(.89 * * *)$ & $.18(.09 * *)$ \\
\hline RFxCF & & $.121\left(.071^{* *}\right)$ & $.092\left(.071^{*}\right)$ & $.084(.074)$ & $.153\left(.083^{* *}\right)$ \\
\hline $\mathrm{RFxCO}$ & & & $.105(.061 * *)$ & $.107(.062 * *)$ & $.10(.062 *)$ \\
\hline CFxCO & & & $.09(.081)$ & $.094(.081)$ & $.094(.081)$ \\
\hline RCxRF & & & & $-.032(.48)$ & $-.069(.052 *)$ \\
\hline $\mathrm{RCxCF}$ & & & & $-.023(.68)$ & $.023(.07)$ \\
\hline RAxRF & & & & & $.214\left(.115^{* *}\right)$ \\
\hline RAxCF & & & & & $-.049(.105)$ \\
\hline \multicolumn{6}{|l|}{ Control Variables: } \\
\hline Environmental dynamism & $-.086(.053 *)$ & $-.069\left(.053^{*}\right)$ & $-.075\left(.053^{*}\right)$ & $-.075(.054 *)$ & $-.081(.054 *)$ \\
\hline Type of goods transacted & $.001(.002)$ & $.001(.002)$ & $.00(.002)$ & $.001(.002)$ & $.001(.002)$ \\
\hline \multicolumn{6}{|l|}{ Industry variables: } \\
\hline Food industry & $-.138(.253)$ & $-.113(.248)$ & $-.083(.247)$ & $-.094(.248)$ & $-.043(.249)$ \\
\hline Apparel industry & $1.264(.735 *)$ & $1.225(.719 * *)$ & $.975(.722 *)$ & $.978\left(.725^{*}\right)$ & $1.12\left(.731^{*}\right)$ \\
\hline Wood industry & $-.053(.606)$ & $-1.38(.595)$ & $-.165(.59)$ & $-.191(.594)$ & $-.238(.592)$ \\
\hline Paper industry & $.358(.599)$ & $.291(.586)$ & $.217(.584)$ & $.188(.589)$ & $.194(.587)$ \\
\hline Printing industry & $.206(.489)$ & $.184(.481)$ & $.104(.478)$ & $.115(.481)$ & $.153(.48)$ \\
\hline Chemical industry & $.024(.212)$ & $-.007(.207)$ & $.041(.207)$ & $.023(.209)$ & $.018(.209)$ \\
\hline Stone industry & $-.074(.287)$ & $.05(.283)$ & $.179(.287)$ & $.141(.295)$ & $.133(.294)$ \\
\hline Metal industry & $-.157(.404)$ & $-.076(.397)$ & $-.088(.395)$ & $-.097(.398)$ & $-.047(.398)$ \\
\hline Machine industry & $-.227(.224)$ & $-.206(.223)$ & $-.210(.221)$ & $-.222(.223)$ & $-.156(.225)$ \\
\hline Medical industry & $.351(.403)$ & $.330(.394)$ & $.306(.392)$ & $.291(.394)$ & $.274(.393)$ \\
\hline Electronics industry & $-.215(.305)$ & $-.209(.298)$ & $-.199(.296)$ & $-.216(.299)$ & $-.206(.298)$ \\
\hline Sales department size & $-.137(.108)$ & $-.175(.107)$ & $-.20(.107)$ & $-.193(.107)$ & $-.192(.107)$ \\
\hline Company experience & $-.001(.001)$ & $.00(.001)$ & $.00(.001)$ & $-.001(.001)$ & $-.001(.001)$ \\
\hline $\mathrm{CO}$ & $.081(.061 *)$ & $.056(.06)$ & $.06(.06)$ & $.046(.06)$ & $.036(.061)$ \\
\hline Role conflict & $-.091(.061 *)$ & $-.099\left(.06^{*}\right)$ & $-.089\left(.061^{*}\right)$ & $-.097(.061 *)$ & $-.108(.062 *)$ \\
\hline Role ambiguity & $-.297(.092 * * *)$ & $-.197(.096 * *)$ & $-1.93(.096 * *)$ & $-.179(.098 * *)$ & $-.185(.098 * *)$ \\
\hline $\mathrm{R}^{2}:$ & .120 & .173 & .193 & .195 & .208 \\
\hline$\Delta \mathrm{F}:$ & 1.598 & $4.356 * *$ & $2.573^{*}$ & .247 & 1.717 \\
\hline
\end{tabular}

Note: RF-Resource flexibility; CF-Configurational flexibility; RC-Role conflict; RA-Role ambiguity; CO-Customer orientation; Standard errors are in parentheses. Coefficients are unstandardized. ${ }^{* * *} \mathrm{p}<.01 ; * * \mathrm{p}<.05 ;{ }^{*} \mathrm{p}<.10$ 
the study results indicate that SIF interacting with CO is associated with lower sales performance; that is, $\mathrm{RFxCO}$ is significant and negative $(\mathrm{p}<.05)$. High $\mathrm{CO}$ requires that the sales function put the customer first, prioritizing customers' needs and wants over other strategic objectives, and provides a focus - a strategic orientation - guiding the setting and direction of goals, and shaping the coordinated deployment of the sales function activities and its resources. High CO provides a mechanism to ensure that SIF activities are focused on providing customer value. This latter (external) focus may mean that the firm forfeits short term internal goals (e.g. sales volume objectives or sales growth objectives) if the internal goals are at odds with the core remit of enhancing customer value. Under high levels of CO and high SIF, the sales function deploys its resources in coordinated and flexible ways to achieve customer-centric goals, and so should find it easier to translate its actions into customer-centric outcomes, but simultaneously, higher SIF under high CO does not guarantee that internal goals (e.g. sales volume, market share) will be achieved. Conversely, when the firm's CO is lower, the organizational focus is shifted away from customer satisfaction and loyalty metrics, and is more intensely targeted at "harder" sales-oriented outcomes. The upshot is that the positive relationship between SIF and sales is stronger when $\mathrm{CO}$ is lower, because sales people can marshal resources to achieve their sales objectives.

In H3 we argue that when levels of SIF are higher, salespeople have greater access to resources and configuration abilities to handle role stresses - ambiguity and conflict - that might otherwise be deleterious to performance. In terms of the hypothesized positive moderating effect of SIF on the relationship between RC and sales and customer performance, none of the hypothesized relationships are significant. The results therefore do not provide evidence to support the notion that SIF alleviates the downsides of role conflict. On the one hand, SIF may 
enhance the ability of salespeople to resolve role conflicts. But on the other hand, under high RC, salespeople may fail to recognize that SIF resources are available (e.g. Brown, Jones, \& Leigh, 2005), and so rather than harvesting SIF, RC may condition salespeople to shy away from utilizing SIF resources (c.f. Netemeyer, Maxham, \& Pullig 2005). Additional research is needed on this front.

In respect of the interrelationships between RA, SIF and performance, we received mixed results and not all the relationships are in the expected direction. For example, for RA, and contrary to expectation, we find a direct, positive relationship between RA and sales performance $(\mathrm{p}<.05)$. This might indicate that, for some sales people, a certain degree of role ambiguity is an essential and desirable component of the job - keeping the working environment challenging and interesting (Nygaard \& Dahlstrom, 2002), and so benefitting performance. Boundary spanning salespeople high in this type of tolerance can still be confident about their decisions and are more likely to engage in creative and novel ways of doing things (Tuckman, 1966), and arguably even more so when flexible resources (RF, here) are available to "hedge" options, and offer increased scope to improve their performance. And, indeed, this logic is supported by the significant moderating effect of RF on RA in predicting sales performance $(\mathrm{p}<.01)$.

Further, in $\mathrm{H} 3$ we argue for positive moderating effects of CF on the RA-sales and RAcustomer performance links. For customer performance, moderation is not supported (see Table 3b, Model 3). Also, contrary to H3, we found that the positive relationship between RA and sales performance is lower under high levels of $\mathrm{CF}(\mathrm{p}<.01)$. Potentially, since SIF may bring with it greater decision-making responsibility, it may be that high CF brings with it greater potential for intensifying the downsides of RA; for example, coordinating the focus of resources on specific 
tasks or outcomes may decrease the ability of salespeople to find the novel, creative solutions required to convert an ambiguous working environment into positive effects for customers.

Certainly, future research could usefully investigate in more depth how CF interacts with RA to shape sales outcomes.

To further explore these moderating relationships, we plotted interaction effects in Fig.s 2a-2f following Aiken and West’s (1991) approach. As Fig.s 2a and 2b for example show, when CF is high, RF has a stronger relationship with both sales and customer performance, respectively. Fig. 2c highlights that when CO levels are high, RF has a weaker effect on sales performance; whereas, Fig. 2d shows a positive moderation of $\mathrm{CO}$ on the relationship between RF and customer performance. Fig. 2e shows positive moderating effects of RF on RA-sales performance, implying that in sales teams with higher RF, the effect of RA on sales performance is stronger. Conversely, Fig. $2 \mathrm{f}$ illustrates an inverse effect of CF on the RA-sales performance relationship. Thus we infer that RF is a more effective predictor of 1) sales and customer performance at high levels of CF, of 2) sales performance when customer orientation is low and for customer performance when customer orientation is high, and RA is more beneficial to sales performance when RF levels are high.

\section{Discussion}

In this study, we set out to examine the value of flexibility (SIF) in the use of sales unit resources. This research is the first of its kind in the sales literature, since SIF has never been (a) explicitly conceptualized in the past, (b) placed in a conceptual model in which its performance outcomes are speculated upon, (c) empirically assessed, and (d) tested as a potential performance 
driver. Our research design encompasses all of these things.

Fig. 2a. -2f Interaction effects.

a) Moderating effect of CF on RF-sales performance link

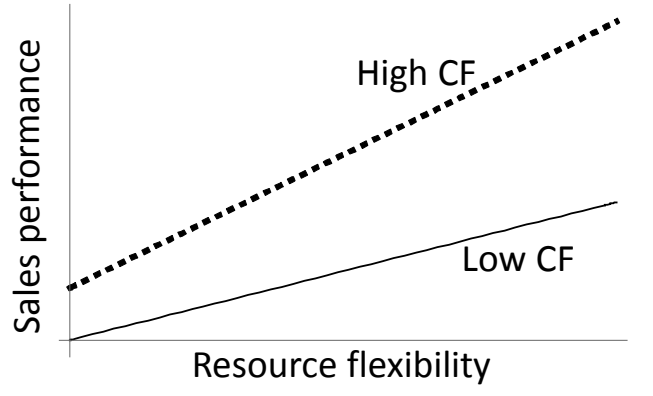

c) Moderating effect of $\mathrm{CO}$ on RF-sales performance link

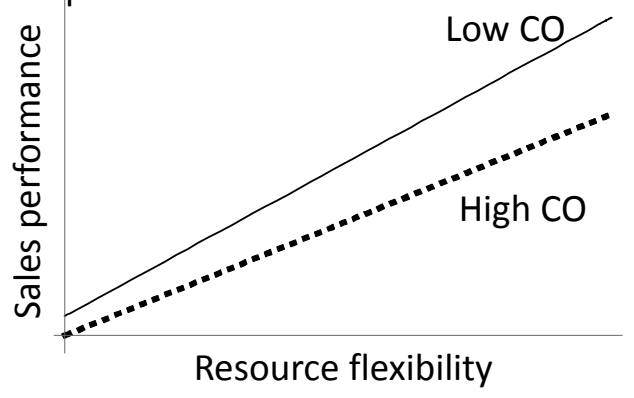

e) Moderating effect of RF on RA-sales

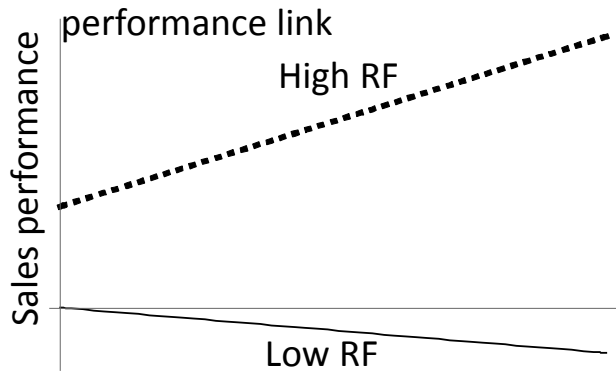

Role ambiguity b) Moderating effect of CF on RF-customer performance link

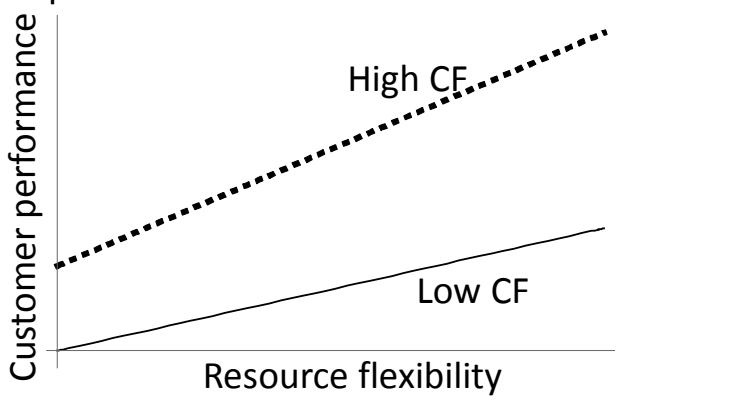

d) Moderating effect of CO on RF-customer

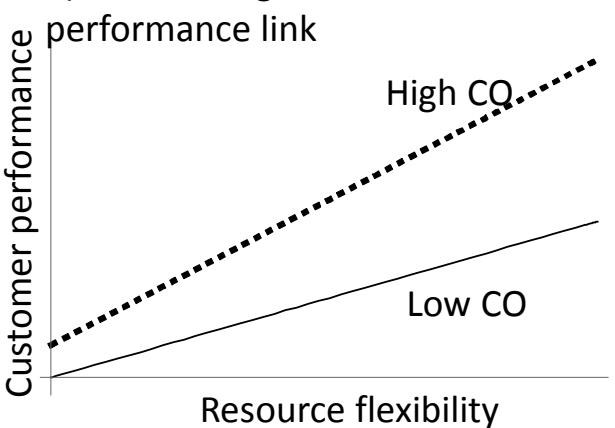

f) Moderating effect of CF on RA-sales

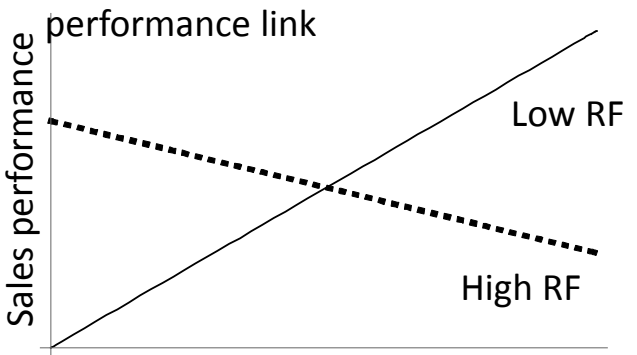

Role ambiguity

Specifically, we focus on identifying and conceptualizing the notion of flexibility in resource management within sales units and examining whether this flexibility within sales units is related to sales and customer performance. We also explore whether the nature of this 
relationship depends on a boundary condition - customer orientation, and whether flexibility itself shapes the relationship between role stress and sales team performance. Our findings have implications for managers and sales researchers.

\subsection{Implications for theory}

First, our efforts show the value of SIF and its two constituent facets (resource and configurational flexibility) in its direct relationship to sales and customer performance. To the extent that it operates in both direct and moderated ways, our results indicate that the SIF relationship with performance is a complex one. As a result, this study contributes to greater understanding of how SIF and its two constituents operate to shape sales and customer performance outcomes.

Second, with regard to the nature of these relationships, the study also points towards an important sales role boundary condition that moderates SIF's relationship to performance customer orientation (CO). In this respect, different levels of customer orientation work to enhance SIF’s link to performance, such that when interacting with resource flexibility, both sales (at low levels of CO) and customer performance (at high levels of CO) are enhanced.

Third and at the same time, SIF does not only have a direct but also a moderating role. In this way, SIF when combined with role ambiguity was successful in helping us identify the context in which role ambiguity would be more or less beneficial to sales performance. 


\subsection{Implications for practitioners}

Our study findings are also relevant for managers. Our study identifies a core capability that may help make sales teams more effective, and even these preliminary findings should give managers confidence to actively encourage SIF within a sales team. The findings are consistent with the notion that when managers invest their efforts in creating a working environment conducive to flexible resource exchange between its salespeople, the sales unit is more successful in finding ways to leverage sales and market share growth and in capturing customers' tastes and requirements. Managers are advised to encourage their salespeople to, (a) view sales team resources as a pool of collective resources which all members of the sales team can tap into, (b) recognize that resources can be shifted from one use to another use (i.e. resource flexibility), and (c) develop the capacity to influence or shape how the redeployed resources are used (i.e. configurational flexibility). A practical illustration of this, and predicated on the view that the firm's overall sales achievements take precedence over those for any one customer account, could be one key account management team working to secure agreement for a mid-year redeployment of promotional budget to the key account from the overall sales unit's previously allocated annual budget. A further example could be salespeople working intra-functionally to influence a shift of people-time and skills from one sales region to an under-performing one.

However, the task of management is to ensure that a sales team's SIF is managed carefully, recognizing that high levels of SIF may not always be the best strategy. In this respect, consideration of strategic orientation (CO) and job characteristics (role stress levels) are required to determine the best SIF for the organization. In respect of $\mathrm{CO}$, RF is a predictor of sales performance when $\mathrm{CO}$ is low and for customer performance when $\mathrm{CO}$ is high. The implications 
are clear for managers whose task is to ensure greater customer performance, such that they must simultaneously increase levels of CO and RF in their sales unit. On the other hand, managers should be aware of the trade-off between the two in the case of their joint effect on sales performance. It is critical for managers to determine the levels of $\mathrm{CO}$ and RF in their sales unit. Focusing predominantly on achieving sales targets can be negatively impacted by $\mathrm{CO}$ as the resources are drawn from their primary focus of sales goal achievement, effectively spreading their resources too thinly in an endeavor to balance one with the other. Hence, managers should be mindful of this opportunity cost to sales achievements and decide when the $a$ priori focus should be on achieving customer satisfaction as opposed to a primary focus on sales performance.

In terms of role stress, role ambiguity (RA) is more beneficial to sales performance when resource flexibility levels are high. Managers are therefore advised not to oppress ambiguity as it may keep the sales role and working environment challenging and interesting. Rather managers are advised to complement its effects by encouraging the extent to which salespeople can shift resources from one use to another.

In order to make SIF a more universally appropriate strategy, and recognizing that high customer orientation (CO) may be relatively desirable and role ambiguity relatively hard-wired into the sales job, future research is required to identify mechanisms that enable SIF to operate positively for sales performance when $\mathrm{CO}$ is high, and find methods of reducing the detrimental moderating effect of CF on the RA-sales performance relationship. Some suggestions are presented below. 


\subsection{Limitations and directions for future research}

As a first investigation of intra-functional flexibility in sales, the current study offers valuable insights. However, the study is not without limitations and with it come the directions for future research. Critically, we study sales teams in a cross-sectional survey, noting that teams with greater levels of SIF tend to outperform those with lower levels of SIF. Future research should study changes in SIF over time, identify the levers for shaping SIF levels within the sales force, and study the potential costs and benefits that may arise from intentionally seeking to manage SIF levels.

In terms of enriching the current conceptual model, additional organizational, personal and role specific variables may influence SIF and moderate its performance outcomes. For example, organizations with organic structures emphasize the importance of high adaptiveness and flexibility in the task execution process, as well open communication and organizational integration (Tatikonda \& Rosenthal, 2000), and so organic structures may be suited to leveraging SIF's performance benefits. Second, the flexibility of salespeople might be influenced by supervisory style. Managers who prioritize group goals ahead of personal goals instill group's collectivist values and preferences towards working in groups (e.g. Chen, Chen, \& Meindl, 1998), which can help foster higher levels of SIF. Facilitative management is capable of focusing a team on the need to balance often conflictual issues (Jones, Brown, Zoltners, \& Weitz, 2005), thus potentially helping balance potentially conflicting CO and SIF conditions. However, additional research is needed here to identify if and how managers can assist salespeople to make these judgements and trade-offs. At the level of the individual salesperson, future research might investigate how a salesperson's individual personality makes him/her more or less prone to invest in SIF. Sales literature, for example, introduces the notion of "lone wolves" as individuals 
who in choosing not to relate to others as social entities within the work environment, are especially reluctant to function as a part of a sales team, preferring instead to operate individually (Dixon, Gassenheimer, \& Feldman-Barr, 2003). Hence, although it is acknowledged that people in general tend to reciprocate in their social exchanges (Gouldner, 1960), further research could examine the conditions and instances (both moderating and mediating) in which salespeople are willing to show more or less reciprocity and flexibility in their exchange relationships.

In terms of the unsupported hypotheses related to SIF's interaction with role conflict (RC), future research might explore the role of internal marketing in generating an enhanced sense of togetherness among salespeople (Kadic-Maglajlic, Boso, \& Micevski, 2017). Such an operating context could render salespeople more receptive to the idea of SIF as a resource to help them resolve conflicts arising from their sales roles. In addition, various supervisory variables have been shown to play a role in how salespeople deal with complexities related to their job roles; for example, transformational leader behavior (e.g. Antonakis, Avolio, \& Sivasubramaniam, 2003). Transformational leaders are capable of instilling a higher sense of purpose, and inspire salespeople to perform beyond the minimum job requirements (MacKenzie, Podsakoff, \& Rich, 2001) - thus potentially helping salespeople understand the importance of SIF as a resource they can tap into to alleviate their job demands and to focus on working "smarter" rather than working "harder".

Another promising area of future research might be found in the issues of exploitation, unfairness and asymmetrical power relations (Hardy \& Phillips, 1998) among salespeople. These instances might be seen as a threat to the use of SIF in general and to configurational flexibility (CF) especially, as CF is an influencing and shaping skill. In such situations, CF might not be seen as a good faith intention but as a protection of interests of certain salespeople. Hence, future 
research can look at the boundary conditions in which CF would be seen as a good thing. For example, researchers could look at how the differing values and goals of salespeople within a team affect CF and the ability of it to yield positive outcomes for the entire sales team.

In addition, recent research points to the issues of new technological trends affecting sales activities, such as salesforce automation (SFA), CRM and team virtuality. Research indicates that these tools aimed at increasing sales efficiency could equally be applied in increasing salespeople’s exchange of information and knowledge (Bush, Moore, \& Rocco, 2005). CRM tools, for example, help balance salespeople workload and enable facilitation of sales team crossselling efforts, and ultimately increase salesperson flexibility and responsiveness (Martins, Gilson, \& Maynard, 2004). On the other hand, research points to the potential drawbacks, such as altered interaction style among salespeople (as in the case of virtuality), which adversely affects their collaboration (e.g. Kirkman, Rosen, Tesluk, \& Gibson, 2004; Rico, SanchezManzanares, \& Gibson, 2008). Considering that firms worldwide invest significant sums into SFA (Honeycutt, 2005) and other technological tools, their role in fostering or inhibiting SIF warrants future research attention.

Finally, future research should examine how the specificities and differences in organizational selling contexts may affect the ability of firms to foster and encourage SIF. For example, in a business-to-consumer (B2C) context, salespeople experience a large amount of face-to-face interaction with a variety of customers on a daily basis compared to their businessto-business (B2B) counterparts; this requires salespeople's real-time engagement with customers and proactive response to issues emerging (e.g. Homburg \& Fürst, 2005; Kadic-Maglajlic, Micevski, Arslanagic-Kalajdzic, \& Lee, 2017). In such a setting, less of a salesperson’s time will be available to dedicate to their co-workers and, correspondingly, less to exhibit SIF. Whether 
this type of business setting requires additional organizational, structural and managerial support for encouraging SIF and whether conditions under which SIF is most beneficial in these two settings warrants further research.

\section{References}

Aiken, L. S., \& West, S. G. (1991). Multiple regression: Testing and interpreting interactions. Newbury Park, CA: Sage Publications.

Antonakis, J., Avolio, B. J., \& Sivasubramaniam, N. (2003). Context and leadership: An examination of the nine-factor full-range leadership theory using the Multifactor Leadership Questionnaire. The Leadership Quarterly, 14(3), 261-295.

Bagozzi, R. P., \& Yi, Y. (1988). On the evaluation of structural equation models. Journal of the Academy of Marketing Science, 16(1), 74-94.

Bentler, P. M., \& Chou, C. P. (1987). Practical issues in structural modeling. Sociological Methods \& Research, 16(1), 78-117.

Bercovitz, J., Jap, S. D., \& Nickerson, J. A. (2006). The antecedents and performance implications of cooperative exchange norms. Organization Science, 17(6), 724-740.

Bettencourt, L. A., \& Brown, S. W. (2003). Role stressors and customer-oriented boundaryspanning behaviors in service organizations. Journal of the Academy of Marketing Science, 31(4), 394-408.

Blau, P. M. (1964). Exchange and power in social life. Transaction Publishers.

Bolander, W., \& Richards, K. A. (2018). Why study intraorganizational issues in selling and sales management? Journal of Personal Selling \& Sales Management, 38(2), 169-171. 
Bonney, L., Plouffe, C. R., \& Wolter, J. (2014). “I think I can... I think I can”: The impact of perceived selling efficacy and deal disclosure on salesperson escalation of commitment. Industrial Marketing Management, 43(5), 826-839.

Bradford, K., Brown, S., Ganesan, S., Hunter, G., Onyemah, V., Palmatier, R., Rouziès, D., Spiro, R., Sujan, H., \& Weitz, B. (2010). The embedded sales force: Connecting buying and selling organizations. Marketing Letters, 21(3), 239-253.

Brown, S. P., Jones, E., \& Leigh, T. W. (2005). The attenuating effect of role overload on relationships linking self-efficacy and goal level to work performance. Journal of Applied Psychology, 90(5), 972.

Bush, A. J., Moore, J. B., \& Rocco, R. (2005). Understanding sales force automation outcomes: A managerial perspective. Industrial Marketing Management, 34(4), 369-377.

Cadogan, J. W., Sundqvist, S., Puumalainen, K., \& Salminen, R. T. (2012). Strategic flexibilities and export performance: The moderating roles of export market-oriented behavior and the export environment. European Journal of Marketing, 46(10), 1418-1452.

Cannon, J. P., Achrol, R. S., \& Gundlach, G. T. (2000). Contracts, norms, and plural form governance. Journal of the Academy of Marketing Science, 28(2), 180-194.

Chen, C. C., Chen, X. P., \& Meindl, J. R. (1998). How can cooperation be fostered? The cultural effects of individualism-collectivism. Academy of Management Review, 23(2), 285-304.

Chonko, L. B., \& Jones, E. (2005). The need for speed: Agility selling. Journal of Personal Selling \& Sales Management, 25(4), 371-382.

Cohen, J. (1988). Statistical power analysis for the behavioral sciences. Academic Press, New York.

Dai, Y., Goodale, J. C., Byun, G., \& Ding, F. (2018). Strategic Flexibility in New High - 
Technology Ventures. Journal of Management Studies, 55(2), 265-294.

Davcik, N. S., \& Sharma, P. (2016). Marketing resources, performance, and competitive advantage: A review and future research directions. Journal of Business Research, 69(12), $5547-5552$.

Dixon, A. L., Gassenheimer, J. B., \& Feldman Barr, T. (2003). Identifying the lone wolf: A team perspective. Journal of Personal Selling \& Sales Management, 23(3), 205-219.

Fornell, C., \& Larcker, D. F. (1981). Structural equation models with unobservable variables and measurement error: Algebra and statistics. Journal of marketing research, 18(3), 382-388.

Gouldner, A. W. (1960). The norm of reciprocity: A preliminary statement. American Sociological Review, 25, 161-178.

Grewal, R., \& Tansuhaj, P. (2001). Building organizational capabilities for managing economic crisis: The role of market orientation and strategic flexibility. Journal of Marketing, 65(2), 67-80.

Han, S. L., Sung, H. S., \& Shim, H. S. (2014). Antecedents and performance outcomes of flexibility in industrial customer-supplier relationships. Journal of Business Research, 67(10), 2115-2122.

Hardy, C., \& Phillips, N. (1998). Strategies of engagement: Lessons from the critical examination of collaboration and conflict in an interorganizational domain. Organization Science, 9(2), 217-230.

Homburg, C., \& Jensen, O. (2007). The thought worlds of marketing and sales: which differences make a difference? Journal of Marketing, 71(3), 124-142.

Homburg, C., Müller, M., \& Klarmann, M. (2011). When should the customer really be king? On the optimum level of salesperson customer orientation in sales encounters. Journal of 
Marketing, 75(2), 55-74.

Homburg, C., \& Fürst, A. (2005). How organizational complaint handling drives customer loyalty: an analysis of the mechanistic and the organic approach. Journal of Marketing, 69(3), 95-114.

Honeycutt Jr, E. D. (2005). Technology improves sales performance—doesn't it?: An introduction to the special issue on selling and sales technology. Industrial Marketing Management, 34(4), 301-304.

Hooley, G. J., Greenley, G. E., Cadogan, J. W., \& Fahy, J. (2005). The performance impact of marketing resources. Journal of Business Research, 58(1), 18-27.

Hughes, D. E., Le Bon, J. L., \& Rapp, A. (2013). Gaining and leveraging customer-based competitive intelligence: The pivotal role of social capital and salesperson adaptive selling skills. Journal of the Academy of Marketing Science, 41(1), 91-110.

Jaramillo, F., Mulki, J. P., \& Boles, J. S. (2013). Bringing meaning to the sales job: The effect of ethical climate and customer demandingness. Journal of Business Research, 66(11), 23012307.

Johnson, J. S., \& Sohi, R. S. (2014). The curvilinear and conditional effects of product line breadth on salesperson performance, role stress, and job satisfaction. Journal of the Academy of Marketing Science, 42(1), 71-89.

Jones, E., Brown, S. P., Zoltners, A. A., \& Weitz, B. A. (2005). The changing environment of selling and sales management. Journal of Personal Selling \& Sales Management, 25(2), 105-111.

Jones, E., Chonko, L., Rangarajan, D., \& Roberts, J. (2007). The role of overload on job attitudes, turnover intentions, and salesperson performance. Journal of Business Research, 
60(7), 663-671.

Kadic-Maglajlic, S., Boso, N., \& Micevski, M. (2018). How internal marketing drive customer satisfaction in matured and maturing European markets? Journal of Business Research, 86, 291-299.

Kadic-Maglajlic, S., Micevski, M., Arslanagic-Kalajdzic, M., \& Lee, N. (2017). Customer and selling orientations of retail salespeople and the sales manager's ability-to-perceiveemotions: A multi-level approach. Journal of Business Research, 80, 53-62.

Katsikeas, C. S., Leonidou, L. C., \& Morgan, N. A. (2000). Firm-level export performance assessment: review, evaluation, and development. Journal of the Academy of Marketing Science, 28(4), 493-511.

Katz, D., \& Kahn, R. L. (1978). The social psychology of organizations (Vol. 2). New York: Wiley.

Kirkman, B. L., Rosen, B., Tesluk, P. E., \& Gibson, C. B. (2004). The impact of team empowerment on virtual team performance: The moderating role of face-to-face interaction. Academy of Management Journal, 47(2), 175-192.

Kouropalatis, Y., Hughes, P., \& Morgan, R. E. (2012). Pursuing “flexible commitment” as strategic ambidexterity: An empirical justification in high technology firms. European Journal of Marketing, 46(10), 1389-1417.

Lassala, C., Burrus Jr, R. T., \& Graham, J. E. (2016). Business school grading on both sides of the Atlantic. Journal of Business Research, 69(11), 5106-5110.

Lee, G., \& Xia, W. (2005). The ability of information systems development project teams to respond to business and technology changes: a study of flexibility measures. European Journal of Information Systems, 14(1), 75-92. 
Little, T. D., Bovaird, J. A., \& Widaman, K. F. (2006). On the merits of orthogonalizing powered and product terms: Implications for modeling interactions among latent variables. Structural Equation Modeling, 13(4), 497-519.

Luo, X., Rindfleisch, A., \& Tse, D. K. (2007). Working with rivals: The impact of competitor alliances on financial performance. Journal of Marketing Research, 44(1), 73-83.

MacKenzie, S. B., Podsakoff, P. M., \& Rich, G. A. (2001). Transformational and transactional leadership and salesperson performance. Journal of the Academy of Marketing Science, 29(2), 115.

Martins, L. L., Gilson, L. L., \& Maynard, M. T. (2004). Virtual teams: What do we know and where do we go from here? Journal of Management, 30(6), 805-835.

Mason, K., \& Mouzas, S. (2012). Flexible business models. European Journal of Marketing, 46(10), 1340-1367.

Matzler, K., Sauerwein, E., \& Heischmidt, K. (2003). Importance-performance analysis revisited: the role of the factor structure of customer satisfaction. The Service Industries Journal, 23(2), 112-129.

Morgan, J. (2012). The collaborative organization: A strategic guide to solving your internal business challenges using emerging social and collaborative tools. McGraw-Hill, New York.

Mulki, J. P., Jaramillo, F., Malhotra, S., \& Locander, W. B. (2012). Reluctant employees and felt stress: The moderating impact of manager decisiveness. Journal of Business Research, 65(1), 77-83.

Narver, J. C., \& Slater, S. F. (1990). The effect of a market orientation on business profitability. The Journal of Marketing, 54, 20-35. 
Netemeyer, R. G., Maxham III, J. G., \& Pullig, C. (2005). Conflicts in the work-family interface: Links to job stress, customer service employee performance, and customer purchase intent. Journal of Marketing, 69(2), 130-143.

Nygaard, A., \& Dahlstrom, R. (2002). Role stress and effectiveness in horizontal alliances. Journal of Marketing, 66(2), 61-82.

Ping, R. A. (1995). A parsimonious estimating technique for interaction and quadratic latent variables. Journal of Marketing Research, 32(3), 336-347.

Plouffe, C. R. (2018). Is it navigation, networking, coordination... or what? A multidisciplinary review of influences on the intraorganizational dimension of the sales role and performance. Journal of Personal Selling \& Sales Management, 38(2), 241-264.

Podsakoff, N. P., LePine, J. A., \& LePine, M. A. (2007). Differential challenge stressorhindrance stressor relationships with job attitudes, turnover intentions, turnover, and withdrawal behavior: A meta-analysis. Journal of Applied Psychology, 92(2), 438.

Podsakoff, P. M., MacKenzie, S. B., Lee, J. Y., \& Podsakoff, N. P. (2003). Common method biases in behavioral research: A critical review of the literature and recommended remedies. Journal of Applied Psychology, 88(5), 879.

Poppo, L., Zhou, K. Z., \& Li, J. J. (2016). When can you trust “trust”? Calculative trust, relational trust, and supplier performance. Strategic Management Journal, 37(4), 724-741.

Rangarajan, D., Chonko, L. B., Jones, E., \& Roberts, J. A. (2004). Organizational variables, sales force perceptions of readiness for change, learning, and performance among boundaryspanning teams: A conceptual framework and propositions for research. Industrial Marketing Management, 33(4), 289-305.

Rico, R., Sánchez-Manzanares, M., Gil, F., \& Gibson, C. (2008). Team implicit coordination 
processes: A team knowledge-based approach. Academy of Management Review, 33(1), 163-184.

Rizzo, J. R., House, R. J., \& Lirtzman, S. I. (1970). Role conflict and ambiguity in complex organizations. Administrative Science Quarterly, 15, 150-163.

Román, S., \& Iacobucci, D. (2010). Antecedents and consequences of adaptive selling confidence and behavior: a dyadic analysis of salespeople and their customers. Journal of the Academy of Marketing Science, 38(3), 363-382.

Román, S., Rodríguez, R., \& Jaramillo, J. F. (2018). Are mobile devices a blessing or a curse? Effects of mobile technology use on salesperson role stress and job satisfaction. Journal of Business \& Industrial Marketing, 33(5), 651-664.

Sanchez, R. (1997). Preparing for an uncertain future: Managing organizations for strategic flexibility. International Studies of Management \& Organization, 27(2), 71-94.

Sturman, M. C. (2003). Searching for the inverted U-shaped relationship between time and performance: Meta-analyses of the experience/performance, tenure/performance, and age/performance relationships. Journal of Management, 29(5), 609-640.

Tatikonda, M. V., \& Rosenthal, S. R. (2000). Technology novelty, project complexity, and product development project execution success: a deeper look at task uncertainty in product innovation. IEEE Transactions on engineering management, 47(1), 74-87.

Tuckman, B. W. (1966). Integrative complexity: Its measurement and relation to creativity. Educational and Psychological Measurement, 26(2), 369-382.

Wachner, T., Plouffe, C. R., \& Grégoire, Y. (2009). SOCO's impact on individual sales performance: The integration of selling skills as a missing link. Industrial Marketing Management, 38(1), 32-44. 
Wieseke, J., Ahearne, M., Lam, S. K., \& Dick, R. V. (2009). The role of leaders in internal marketing. Journal of Marketing, 73(2), 123-145. 